\title{
Infectious endophthalmitis leading to evisceration: spectrum of bacterial and fungal pathogens and antibacterial susceptibility profile
}

Tarjani Vivek Dave ${ }^{1}$, Vivek Pravin Dave ${ }^{2 *}$, Savitri Sharma ${ }^{3}$, Roshni Karolia ${ }^{3}$, Joveeta Joseph ${ }^{3}$, Avinash Pathengay ${ }^{4}$, Rajeev R. Pappuru ${ }^{2}$ and Taraprasad Das ${ }^{2}$

\begin{abstract}
Purpose: To describe the spectrum of bacterial and fungal pathogens in cases of endophthalmitis requiring evisceration and report their antimicrobial susceptibilities.

Methods: Retrospective, consecutive, and descriptive case series of endophthalmitis that underwent evisceration from January 2004 to December 2017. Vitreous samples from all patients had been investigated for bacteria and fungus using institutional protocol. Bacterial isolates were identified using analytical profile index (API) system until 2010 and Vitek-2 compact system (bioMérieux, France), thereafter. The susceptibility of bacterial isolates to a variety of antibiotics was determined by the Kirby-Bauer disk-diffusion method.

Results: Of 791 cases reviewed, culture positivity was reported in 388 cases (48.92\%). Commonest clinical setting of endophthalmitis necessitating evisceration was post-microbial keratitis (58\%), followed by post-trauma and postcataract surgery (14-15\%). The commonest isolate was Streptococcus pneumoniae, seen in 68 samples overall (17.52\%). One hundred and eighty-three isolates (47.16\%) were gram-positive, 86 (22.16\%) were gram-negative, and fungi constituted 137 (35.3\%) isolates. Streptococcus pneumoniae was the commonest gram-positive bacterial isolate seen in 68/183 samples (37.15\%). Among gram-negative organisms, the commonest was Pseudomonas aeruginosa seen in 47/86 (54.65\%). Aspergillus spp. formed the commonest fungal isolate, 58/137 (42.33\%). The susceptibility of the grampositive bacteria was highest with vancomycin, 136/147 (92.51\%) and for gram-negative bacteria was seen best with imipenem 24/29 (82.75\%). Susceptibility to ceftazidime was 31/61 (50.81\%) in 31/61.
\end{abstract}

Conclusion: Endophthalmitis due to Pneumococci, Aspergillus, and Pseudomonas can be very fulminant and progress to require evisceration in spite of prompt and appropriate treatment.

Keywords: Endophthalmitis, Evisceration, Microbiologic profile

\section{Summary statement}

Endophthalmitis is the most severe form of intraocular infection. Due to multiple factors, sometimes the infections progress in spite of timely and appropriate management and necessitates evisceration. The current paper discusses the clinical setting, microbiologic

\footnotetext{
* Correspondence: vivekoperates@yahoo.co.in

${ }^{2}$ Smt. Kanuri Santhamma Center for Vitreoretinal Diseases, KallamAnji Reddy

Campus, LV Prasad Eye Institute, Hyderabad, Telangana 500034, India

Full list of author information is available at the end of the article
}

profile, and antibiotic susceptibility pattern of cases of endophthalmitis that required evisceration.

\section{Introduction}

Endophthalmitis is an ocular condition characterized by inflammation of the inner coats of the eye followed by exudation in the vitreous cavity [1]. It necessitates prompt and early management with intraocular antibiotics often combined with a pars plana vitrectomy. Many a times, in spite of prompt management, the condition may progress and either cause a painful blind eye or 
convert into a panophthalmitis with the infection spreading to the sclera and the Tenon's capsule. In such situations, the eye often needs to undergo evisceration $[2,3] . \mathrm{Lu}$, et al. in their paper on risk factors for endophthalmitis requiring evisceration or enucleation described an evisceration rate of $14.3 \%$ [2]. Tsai, et al. in their paper on the same subject reported a higher evisceration/enucleation rate of $23.2 \%$ [3].

The probable reasons for the progression in spite of prompt and appropriate management could include relatively virulent organisms with possible high antibiotic resistance pattern. Current existing literature does not have adequate description about the spectrum of causative organisms and their antimicrobial susceptibility patterns in cases of endophthalmitis that eventually require evisceration. In the current communication, we report the above in such cases treated at our center over the past decade.

\section{Materials and methods}

This is a retrospective, non-comparative, descriptive, consecutive case series of patients treated at L.V. Prasad Eye Institute, Hyderabad, India, both in-house and referred from January 2004 to December 2017. The microbiology records of all cases of endophthalmitis that underwent evisceration were reviewed. The study was approved by the Institutional Review Board, and it adhered to the Tenets of the Declaration of Helsinki. Vitreous samples from all patients had been investigated for bacteria and fungus using institutional protocol [4]. Bacterial isolates were identified using analytical profile index (API) system until 2010 and Vitek-2 compact system (bioMérieux, France), thereafter. The susceptibility of bacterial isolates to a variety of antibiotics was determined by the Kirby-Bauer disk-diffusion method. Fungal species were identified based on their colony and microscopic characteristics. Susceptibility test for fungal isolates were not performed.

Eviscerated samples were transported to the microbiology laboratory immediately in a sterile bottle. The sample was examined by direct microscopy (Calcofluor-white, Gram, Giemsa stains) and culture for aerobic and anaerobic organisms. Special stains such as modified Ziehl-Neelsen using $1 \% \mathrm{H}_{2} \mathrm{SO}_{4}$ and Gomori methenamine Silver stain were done for microscopy when indicated. For culture, the sample was inoculated on 5\% sheep blood agar, 5\% sheep blood chocolate agar, brain heart infusion broth, thioglycollate broth, and Sabouraud dextrose agar (SDA). All media were incubated at $37^{\circ} \mathrm{C}$ for 1 week except SDA, which was incubated at $27^{\circ} \mathrm{C}$ for 2 weeks for the isolation of fungi. Growth on two or more media or confluent growth on at least one solid medium at the site of inoculation or growth on one medium with consistent direct microscopy result was defined as a significant positive culture and was included in the study.

\section{Results}

A total of 6158 cases of endophthalmitis were seen at our center along the time period from January 2004 to December 2017. Of these, 791 cases of endophthalmitis underwent evisceration (12.84\%). Of these cultures, positivity was reported in 388 cases (48.92\%). Table 1 shows the various clinical etiologies that led to eventual evisceration. The commonest clinical setting of endophthalmitis necessitating evisceration was post-microbial keratitis which accounted for more than half $(58 \%)$ of all the cases. This was followed by endophthalmitis posttrauma and post-cataract surgery (14-15\%). Of the total 388 culture positive cases, the commonest isolate reported was Streptococcus pneumoniae, seen in 68 samples overall (17.52\%). One hundred and eighty-three isolates $(47.16 \%)$ were gram-positive organisms, 86 $(22.16 \%)$ were gram-negative organisms, and fungi constituted 137 (35.3\%) isolates. Among gram-positive organisms, Streptococcus pneumoniae was the commonest gram-positive bacterial isolate and the commonest gram-positive coccus seen in 68/183 samples (37.15\%). The commonest gram-positive bacillus was Bacillus species 6/183 samples (6.55\%). Among gram-negative organisms, the commonest isolate was Pseudomonas aeruginosa seen in 47/86 (54.65\%). Aspergillus spp. formed the commonest isolate among fungi, 58/137 (42.33\%). The detailed isolate list is described in Table 2.

The susceptibility of the gram-positive bacteria was highest with vancomycin, 136/147 samples tested (92.51\%) followed by cefazolin118/149 samples tested (79.19\%). That for gram-negative bacteria was seen best with imipenem $24 / 29$ samples tested (82.75\%) followed by gatifloxacin $137 / 196$ samples tested (69.89\%), moxifloxacin101/158 samples tested (63.92\%), and ofloxacin $118 / 199$ samples tested (59.29\%). Susceptibility to ceftazidime was found to be $50.81 \%$ in $31 / 61$ samples tested. The detailed susceptibility list is described in Table 3.

\section{Discussion}

The current study showed that the commonest isolate in cases of endophthalmitis undergoing evisceration was Streptococcus pneumoniae followed by Aspergillus and

Table 1 Etiology of endophthalmitis undergoing evisceration

\begin{tabular}{ll}
\hline Etiology & Number (\%) \\
\hline Post cataract surgery & $55(14.17)$ \\
Post trauma & $56(14.43)$ \\
Endogenous & $22(5.67)$ \\
Post keratoplasty & $29(7.47)$ \\
Post keratitis and perforation & $226(58.24)$ \\
\hline
\end{tabular}


Table 2 Spectrum of organisms isolated from the evisceration contents

\begin{tabular}{|c|c|c|}
\hline & Organism & $\begin{array}{l}\text { Number } \\
(\%)\end{array}$ \\
\hline \multirow{17}{*}{$\begin{array}{l}\text { Gram-positive organisms } \\
(n=183)\end{array}$} & Streptococcus pneumoniae & 68 (37.15) \\
\hline & Staphylococcus epidermidis & $31(16.93)$ \\
\hline & Staphylococcus aureus & $22(12.02)$ \\
\hline & Bacillus spp. & $12(6.55)$ \\
\hline & B-hemolytic Streptococci & $12(6.55)$ \\
\hline & Corynebacterium spp. & $10(5.46)$ \\
\hline & a- hemolytic streptococci & $7(3.82)$ \\
\hline & Staphylococcus spp. & $5(2.73)$ \\
\hline & $\begin{array}{l}\text { Coagulase-negative } \\
\text { staphylococci }\end{array}$ & $4(2.18)$ \\
\hline & Non-hemolytic Streptococci & $3(1.63)$ \\
\hline & Leuconostoc spp. & $2(1.09)$ \\
\hline & Brevibacterium spp. & $2(1.09)$ \\
\hline & Enteorcoccus spp. & $1(0.54)$ \\
\hline & Kocuriaspp & $1(0.54)$ \\
\hline & Mycobacterium spp. & $1(0.54)$ \\
\hline & Nocardia spp. & $1(0.54)$ \\
\hline & Pentoea spp. & $1(0.54)$ \\
\hline \multirow{12}{*}{$\begin{array}{l}\text { Gram-negative organisms } \\
(n=87)\end{array}$} & Pseudomonas aeruginosa & $47(54.02)$ \\
\hline & Escherechia coli & $11(12.64)$ \\
\hline & Enterobacter spp. & $7(8.04)$ \\
\hline & Hemophilus spp. & $4(4.59)$ \\
\hline & Klebsiella spp. & $4(4.59)$ \\
\hline & Pseudomonas spp. & $4(4.59)$ \\
\hline & Acenitobacter spp. & $3(3.44)$ \\
\hline & Citrobacter spp. & $2(2.29)$ \\
\hline & Serratia spp. & $2(2.29)$ \\
\hline & Burkholderia spp. & $1(1.14)$ \\
\hline & Weeksellavirosa & $1(1.14)$ \\
\hline & $\begin{array}{l}\text { Non-fermenting gram- } \\
\text { negative bacilli }\end{array}$ & $1(1.14)$ \\
\hline \multirow[t]{10}{*}{ Fungi $(n=137)$} & Fusarium spp & 19 (13.86) \\
\hline & Unidentified hyaline fungi & $26(18.97)$ \\
\hline & Aspergillus spp. & $58(42.33)$ \\
\hline & $\begin{array}{l}\text { Unidentified dematecious } \\
\text { fungi }\end{array}$ & $11(8.02)$ \\
\hline & Candida spp. & $3(2.18)$ \\
\hline & Acremonium spp. & $8(5.83)$ \\
\hline & Exserohilum spp. & $2(1.45)$ \\
\hline & Colletotrichum spp. & $2(1.45)$ \\
\hline & Phialophora spp. & $1(0.72)$ \\
\hline & Alternaria spp. & $1(0.72)$ \\
\hline
\end{tabular}

Table 2 Spectrum of organisms isolated from the evisceration contents (Continued)

\begin{tabular}{lll}
\hline & Organism & $\begin{array}{l}\text { Number } \\
(\%)\end{array}$ \\
\hline & Penicillium spp. & $1(0.72)$ \\
& Absidia spp. & $1(0.72)$ \\
& Lasiodiplodia spp. & $1(0.72)$ \\
& Curvularia spp. & $1(0.72)$ \\
& Cladosporium spp. & $1(0.72)$ \\
& Mucor & $1(0.72)$ \\
Parasitic organisms $(n=5)$ & Acanthameba spp. & $5(100)$ \\
\hline
\end{tabular}

Pseudomonas aeruginosa respectively. Only one previous study on evisceration following endophthalmitis has discussed the causative organisms [3]. In that study, the authors described 20 eyes that underwent evisceration following endophthalmitis. The commonest reported organism in that subset was Pseudomonas aeruginosa. Aspergillus accounted for one eye whereas Streptococcus pneumoniae was not reported. Studies on endophthalmitis secondary to Streptococcus pneumoniae suggest a poor visual outcome with a high rate of poor anatomic outcome. Miller et al., in their study on pneumococcal endophthalmitis, reported 3/27 (11.11\%) eyes needing evisceration [5].The low evisceration rate in their study could be attributed to the fact that the antimicrobial susceptibilities to the commonly used intravitreal antibiotics like vancomycin, gatifloxacin, cefazolin, and ciprofloxacin, in their study was $100 \%$. Conversely, in the current study, the pneumococcal endophthalmitis subgroup (68 eyes) showed a varied sensitivity pattern to the common antibiotics used. In contrast to Miller et al., in another study by Soriano et al. [6], the evisceration rates in 36 cases of Streptococcus pneumoniae endophthalmitis was $47.22 \%$. This indirectly is in agreement with our study observation that Streptococcus pneumoniae is an important cause of evisceration following endophthalmitis. This relatively poor outcome has been hypothesized due to a very high degree of inflammatory response evoked by Streptococcus pneumoniae by its exotoxins and enzymes [7-10]. A commonly known virulence factor is a polysaccharide capsule that releases pneumococci from the host by preventing phagocytosis. Another potent virulence factor is pneumolysin which inhibits host responses such as antibody synthesis and lymphocyte proliferation. Inflammation is caused by the virulence factor of cell wall components, which are thought to be the main cause of symptoms. Aspergillus is a common organism causing endophthalmitis, more so in the Indian sub-continent as compared to the western world, where molds like Candida form the major etiology of fungal endophthalmitis [11-13]. In cases of fungal 
Table 3 Overall specific antibiotic susceptibilities of the individual bacterial species ${ }^{*}$

\begin{tabular}{|c|c|c|c|c|c|c|c|c|c|c|c|c|c|c|c|c|c|c|c|c|c|c|c|c|}
\hline \multirow[t]{2}{*}{ Species } & \multicolumn{3}{|c|}{ Cefazolin } & \multicolumn{3}{|c|}{ Ceftazidime } & \multicolumn{3}{|c|}{ Chloramphenicol } & \multicolumn{3}{|c|}{ Ciprofloxacin } & \multicolumn{3}{|c|}{ Gatifloxacin } & \multicolumn{3}{|c|}{ Imipenem } & \multicolumn{3}{|c|}{ Tobramycin } & \multicolumn{3}{|c|}{ Vancomycin } \\
\hline & $S$ & 1 & $\mathrm{R}$ & $S$ & I & $\mathrm{R}$ & $S$ & 1 & $\mathrm{R}$ & $S$ & I & $\mathrm{R}$ & $S$ & I & $\mathrm{R}$ & $S$ & I & $\mathrm{R}$ & $S$ & I & $\mathrm{R}$ & $S$ & I & $\mathrm{R}$ \\
\hline \multicolumn{25}{|c|}{ Gram-positive bacteria ( $n=$ number tested)) } \\
\hline Streptococcus pneumoniae & 54 & 0 & 0 & 1 & 0 & 0 & 53 & 0 & 1 & 46 & 6 & 1 & 47 & 3 & 1 & 0 & 0 & 0 & 0 & 0 & 0 & 51 & 0 & 1 \\
\hline Streptococcus spp. (14) & 7 & 0 & 0 & 1 & 0 & 0 & 7 & 0 & 7 & 3 & 0 & 3 & 7 & 0 & 1 & 0 & 0 & 0 & 0 & 1 & 0 & 7 & 0 & 0 \\
\hline Staphylococcus epidermidis (23) & 19 & 2 & 1 & 0 & 0 & 0 & 19 & 0 & 4 & 6 & 4 & 13 & 18 & 1 & 4 & 0 & 0 & 0 & 0 & 0 & 0 & 22 & 0 & 0 \\
\hline Staphylococcus aureus (14) & 10 & 2 & 2 & 0 & 0 & 0 & 14 & 0 & 0 & 1 & 0 & 13 & 10 & 2 & 2 & 0 & 0 & 0 & 0 & 0 & 0 & 13 & 0 & 0 \\
\hline Bacillus spp. (7) & 1 & 0 & 2 & 0 & 0 & 1 & 3 & 0 & 0 & 7 & 0 & 0 & 7 & 0 & 0 & 0 & 0 & 0 & 0 & 0 & 0 & 7 & 0 & 0 \\
\hline B-hemolytic Streptococci (6) & 6 & 0 & 0 & 1 & 0 & 0 & 5 & 0 & 1 & 2 & 1 & 3 & 3 & 0 & 3 & 0 & 0 & 0 & 0 & 0 & 0 & 5 & 0 & 0 \\
\hline Corynebacterium spp. (6) & 4 & 0 & 0 & 0 & 0 & 0 & 4 & 0 & 0 & 2 & 0 & 4 & 0 & 0 & 2 & 0 & 0 & 0 & 0 & 0 & 0 & 6 & 0 & 0 \\
\hline a-hemolytic streptococci (2) & 0 & 0 & 2 & 0 & 0 & 0 & 0 & 2 & 0 & 2 & 0 & 0 & 2 & 0 & 0 & 0 & 0 & 0 & 0 & 0 & 0 & 2 & 0 & 0 \\
\hline Staphylococcus spp. (5) & 3 & 0 & 2 & 0 & 0 & 0 & 1 & 0 & 0 & 0 & 2 & 3 & 2 & 1 & 2 & 0 & 0 & 0 & 0 & 0 & 0 & 4 & 0 & 1 \\
\hline $\begin{array}{l}\text { Coagulase-negative staphylococci } \\
\text { (4) }\end{array}$ & 4 & 0 & 0 & 0 & 0 & 0 & 3 & 0 & 1 & 0 & 1 & 3 & 4 & 0 & 0 & 0 & 0 & 0 & 0 & 0 & 0 & 3 & 0 & 1 \\
\hline Non-hemolytic Streptococci (6) & 1 & 1 & 0 & 0 & 0 & 0 & 1 & 0 & 1 & 3 & 0 & 3 & 1 & 0 & 1 & 0 & 0 & 0 & 0 & 0 & 0 & 2 & 0 & 0 \\
\hline Leuconostoc spp. (2) & 2 & 0 & 0 & 0 & 0 & 0 & 2 & 0 & 0 & 2 & 0 & 0 & 1 & 0 & 1 & 0 & 0 & 0 & 0 & 0 & 0 & 2 & 0 & 0 \\
\hline Brevibacterium spp. (2) & 1 & 0 & 1 & 1 & 0 & 0 & 2 & 0 & 0 & 1 & 0 & 1 & 1 & 0 & 1 & 0 & 0 & 0 & 0 & 0 & 0 & 1 & 0 & 1 \\
\hline Enteorcoccus spp. (1) & 0 & 0 & 1 & 0 & 0 & 0 & 1 & 0 & 0 & 0 & 0 & 1 & 0 & 0 & 1 & 0 & 0 & 0 & 0 & 0 & 0 & 1 & 0 & 0 \\
\hline Kocuria spp. (1) & 0 & 0 & 1 & 0 & 0 & 0 & 1 & 0 & 0 & 0 & 0 & 1 & 1 & 0 & 0 & 0 & 0 & 0 & 0 & 0 & 0 & 1 & 0 & 0 \\
\hline Mycobacterium spp. & 0 & 0 & 0 & 0 & 0 & 0 & 0 & 0 & 0 & 0 & 0 & 0 & 0 & 0 & 0 & 0 & 0 & 0 & 0 & 0 & 0 & 0 & 0 & 0 \\
\hline Nocardia spp. (1) & 0 & 0 & 1 & 0 & 0 & 1 & 0 & 1 & 0 & 0 & 1 & 0 & 0 & 1 & 0 & 0 & 0 & 0 & 0 & 0 & 0 & 1 & 0 & 0 \\
\hline Pentoea spp. (1) & 0 & 0 & 0 & 0 & 0 & 1 & 1 & 0 & 0 & 0 & 1 & 0 & 0 & 1 & 0 & 0 & 0 & 0 & 1 & 0 & 0 & 0 & 0 & 0 \\
\hline \multicolumn{25}{|l|}{ Gram-negative bacteria } \\
\hline Pseudomonas aeruginosa (33) & 0 & 0 & 7 & 14 & 2 & 14 & 2 & 2 & 29 & 17 & 0 & 16 & 15 & 1 & 17 & 17 & 0 & 3 & 6 & 0 & 10 & 0 & 0 & 6 \\
\hline Escherechia coli (6) & 0 & 0 & 0 & 2 & 0 & 4 & 6 & 0 & 0 & 2 & 0 & 4 & 2 & 1 & 3 & 3 & 0 & 0 & 1 & 0 & 2 & 0 & 0 & 0 \\
\hline Enterobacter spp. (2) & 1 & 0 & 0 & 1 & 0 & 1 & 2 & 0 & 0 & 2 & 0 & 0 & 2 & 0 & 0 & 1 & 0 & 0 & 1 & 0 & 0 & 1 & 0 & 0 \\
\hline Hemophilus spp. (2) & 0 & 0 & 0 & 1 & 0 & 0 & 2 & 0 & 0 & 0 & 0 & 1 & 2 & 0 & 0 & 1 & 0 & 0 & 1 & 0 & 0 & 0 & 0 & 0 \\
\hline Klebsiella spp. (2) & 0 & 0 & 0 & 1 & 0 & 1 & 0 & 0 & 0 & 1 & 0 & 1 & 1 & 0 & 1 & 0 & 1 & 0 & 1 & 0 & 0 & 0 & 0 & 0 \\
\hline Pseudomonas spp. (4) & 0 & 0 & 1 & 3 & 0 & 1 & 1 & 0 & 3 & 0 & 0 & 4 & 2 & 0 & 1 & 0 & 0 & 1 & 1 & 0 & 1 & 0 & 0 & 1 \\
\hline Acenitobacter spp. (0) & 0 & 0 & 0 & 0 & 0 & 0 & 0 & 0 & 0 & 0 & 0 & 0 & 0 & 0 & 0 & 0 & 0 & 0 & 0 & 0 & 0 & 0 & 0 & 0 \\
\hline Citrobacter spp. (1) & 0 & 0 & 0 & 1 & 0 & 0 & 1 & 0 & 0 & 1 & 0 & 0 & 1 & 0 & 0 & 0 & 0 & 0 & 0 & 0 & 0 & 0 & 0 & 0 \\
\hline Serratia spp. (1) & 0 & 0 & 0 & 1 & 0 & 0 & 1 & 0 & 0 & 0 & 0 & 1 & 1 & 0 & 0 & 0 & 0 & 0 & 1 & 0 & 0 & 0 & 0 & 0 \\
\hline Burkholderia spp. (1) & 0 & 0 & 0 & 0 & 0 & 1 & 0 & 0 & 1 & 0 & 0 & 1 & 0 & 0 & 1 & 1 & 0 & 0 & 0 & 0 & 1 & 0 & 0 & 0 \\
\hline $\begin{array}{l}\text { Non-fermenting gram-negative ba- } \\
\text { cilli (1) }\end{array}$ & 0 & 0 & 0 & 1 & 0 & 0 & 1 & 0 & 0 & 1 & 0 & 0 & 1 & 0 & 0 & 0 & 0 & 0 & 0 & 0 & 0 & 0 & 0 & 0 \\
\hline Weeksellavirosa (1) & 1 & 0 & 0 & 0 & 0 & 0 & 1 & 0 & 0 & 1 & 0 & 0 & 1 & 0 & 0 & 0 & 0 & 0 & 0 & 0 & 0 & 1 & 0 & 0 \\
\hline Total & 123 & 5 & 20 & 29 & 2 & 25 & 134 & 5 & 48 & 100 & 16 & 77 & 132 & 11 & 42 & 23 & 1 & 4 & 13 & 1 & 14 & 130 & 0 & 11 \\
\hline
\end{tabular}

*Not all samples were tested for all antibiotics

endophthalmitis especially with filamentous fungi, evisceration or enucleation rates as high as $25 \%$ have been reported [12, 13]. Occurrence in immuno-competent individuals common in the Indian sub-continent and a low index of suspicion initially often leads to a delay in the diagnosis of fungal endophthalmitis. This delay especially in case of Aspergillus like fungi can cause widespread vascular spread and intraocular tissue necrosis causing loss of anatomic integrity and necessitating evisceration [14].

EIfrig et al [15] in their study on Pseudomonas endophthalmitis reported an evisceration/enucleation rate of 64\%. Similarly, high evisceration rates post Pseudomonas endophthalmitis were also reported by other workers [16, 17].This is attributable to the widespread and rapid tissue necrosis caused by Pseudomonas toxins. 
These toxins are known to disrupt cellular membranes and epithelial barriers and cause cytotoxicity $[18,19]$.

The current study specifically looked at the microbiologic profile and antibiotic susceptibility pattern of bacteria associated with endophthalmitis that underwent evisceration. The study also shows that the commonest predisposing clinical setting that culminates into need for evisceration is endophthalmitis following keratitis and perforated corneal ulcer. Other than the microbiologic profile, various other clinical factors like duration of the infection, etiology of endophthalmitis, type of treatment, associated trauma, and comorbid systemic factors may have a role in the final outcome, but the current study was not designed to look at those factors. In conclusion, the current communication suggests that though traditionally speaking gram-positive bacterial endophthalmitis has a relatively better treatment outcome as compared to gram-negative endophthalmitis, in cases progressing the evisceration, the incidence of Streptococcus pneumonia, Pseudomonas, and Aspergillus was very high.

\section{Acknowledgements}

Not applicable.

\section{Funding}

Funding was received from the Hyderabad Eye Research foundation

to analyze the microbiology samples.

\section{Availability of data and materials}

Please contact the corresponding author for data requests.

\section{Disclosures}

None of the authors have any disclosures to make.

\section{Authors' contributions}

VPD carried out the manuscript writing, proofreading, and drafted the final copy. JJ carried out microbiologic assessment. AP and RRP participated in its design and coordination, and helped to draft the manuscript. All authors read and approved the final manuscript.

\section{Ethics approval and consent to participate}

Ethics committee approval was taken from the LV Prasad Eye Institute Hyderabad Ethics committee and Institutional Review Board for this research work. No animals were used in this research.

\section{Consent for publication}

Not applicable as no identity revealing photographs or data of any patient were used in the manuscript.

\section{Competing interests}

The authors declare that they have no competing interests.

\section{Publisher's Note}

Springer Nature remains neutral with regard to jurisdictional claims in published maps and institutional affiliations.

\section{Author details}

'Ophthalmic Plastic Surgery Service, KallamAnji Reddy Campus, LV Prasad Eye Institute, Hyderabad, Telangana, India. ${ }^{2}$ Smt. Kanuri Santhamma Center for Vitreoretinal Diseases, KallamAnji Reddy Campus, LV Prasad Eye Institute, Hyderabad, Telangana 500034, India. ${ }^{3}$ Jhaveri Microbiology Center, Brien Holden Eye Research Center, LV Prasad Eye Institute, Hyderabad, India.

${ }^{4}$ Retina and Uveitis Department, GMR Varalaxmi Campus, LV Prasad Eye
Institute, HanumanthawakaChowk, Visakhapatnam, Andhra Pradesh 530040 India.

Received: 19 October 2018 Accepted: 6 May 2019

Published online: 16 May 2019

References

1. Mamalis N (2002) Endophthalmitis. J Cataract Refrac Surg 28:729-730

2. Lu X, Ng DS, Zheng K, Peng K, Jin C, Xia H et al (2016) Risk factors for endophthalmitis requiring evisceration or enucleation. Sci Rep 15:6

3. Tsai Y, Tseng S (2001) Risk factors in endophthalmitis leading to evisceration or enucleation. Ophthalmic Surg Lasers 32:208-212

4. Kunimoto DY, Das TP, Sharma S, Jalali S, Majji AB, Gopinathan U et al (1999) Microbiologic spectrum and susceptibility of isolates: part 1. Postoperative endophthalmitis. Am J Ophthalmol 128:240-242

5. Miller JJ, Scott IU, Flynn HW Jr, Smiddy WE, Corey RP, Miller D (2004) Endophthalmitis caused by Streptococcus pneumoniae. Am J Ophthalmol 138:231-236

6. Soriano F, Perez-Trallero E, Pallares R, Meseguer MA, Fleites A, Gene A et al (2006) Streptococcus pneumoniae endophthalmitis: a study of 36 cases with special reference to antibiotic resistance and treatment options. Clin Microbiol Infect 12:519-526

7. Chan SM, Hodge WG, Leonard BC (1998) Postoperative Streptococcus pneumoniae endophthalmitis complicated by meningitis. Arch Ophthalmol 116:951-953

8. Shrader SK, Band JD, Lauter CB, Murphy P (1990) The clinical spectrum of endophthalmitis: incidence, predisposing factors, and features influencing outcome. J Infect Dis 162:115-120

9. Rai P, He F, Kwang J, Engelward BP, Chow VTK (2016) Pneumococcalpneumolysin induces DNA damage and cell cycle arrest. Sci Rep 30:22972

10. Paton JC, Rowan-Kelly B, Ferrante A (1984) Activation of human complement by the pneumococcal toxin pneumolysin. Infect Immun 43: 1085-1087

11. Han DP, Wisniewski SR, Wilson LA et al (1996) Spectrum and susceptibilities of micorbiologic isolates in the endophthalmitis vitrectomy study. Am J Ophthalmol 122:1-17

12. Wykoff CC, Flynn HW Jr, Miller D, Scott IU, Alfonso EC (2008) Exogenous fungal endophthalmitis: microbiology and clinical outcomes. Ophthalmology 115:1501-1507

13. Leung EH, Kuriyan AE, Flynn WW Jr, Relhan N, Huang LC, Miller D (2016) Am J Ophthalmol 172:45-50

14. Rao NA, Hidayat A (2000) Trans Am OphthalmolSoc 98:183-194

15. Eifrig C, Scott IU, Flynn HW Jr, Miller D (2003) Endophthalmitis caused by Pseudomonas aeruginosa. Ophthalmology 110:1714-1717

16. Sridhar J, Kuriyan AE, Flynn HW Jr, Miller D (2015) Endophthalmitis caused by Pseudomonas aeruginosa: clinical features, antibiotic susceptibilities and treatment outcomes. Retina 35:1101-1106

17. Falavarjani KG, Alemzadeh SA, Habibi A, Hadavandkhani A, Askari S, Pourhabibi A (2017) Pseudomonas aeruginosa endophthalmitis: clinical outcomes and antibiotic susceptibilities. Ocullmmunollnflamm 25:377-381

18. Soong G, Parker D, Magargee M, Prince A (2008) The type II toxins of Pseudomonas aeruginosa disrupt epithelial barrier function. J Bacteriol 190: 2814-2821

19. Barbieri JT (2000) Pseudomonas aeruginosaExoenxyme $S$, a bifunctional type-III secreted cytotoxin. Int J Med Microbiol 290:381-387 